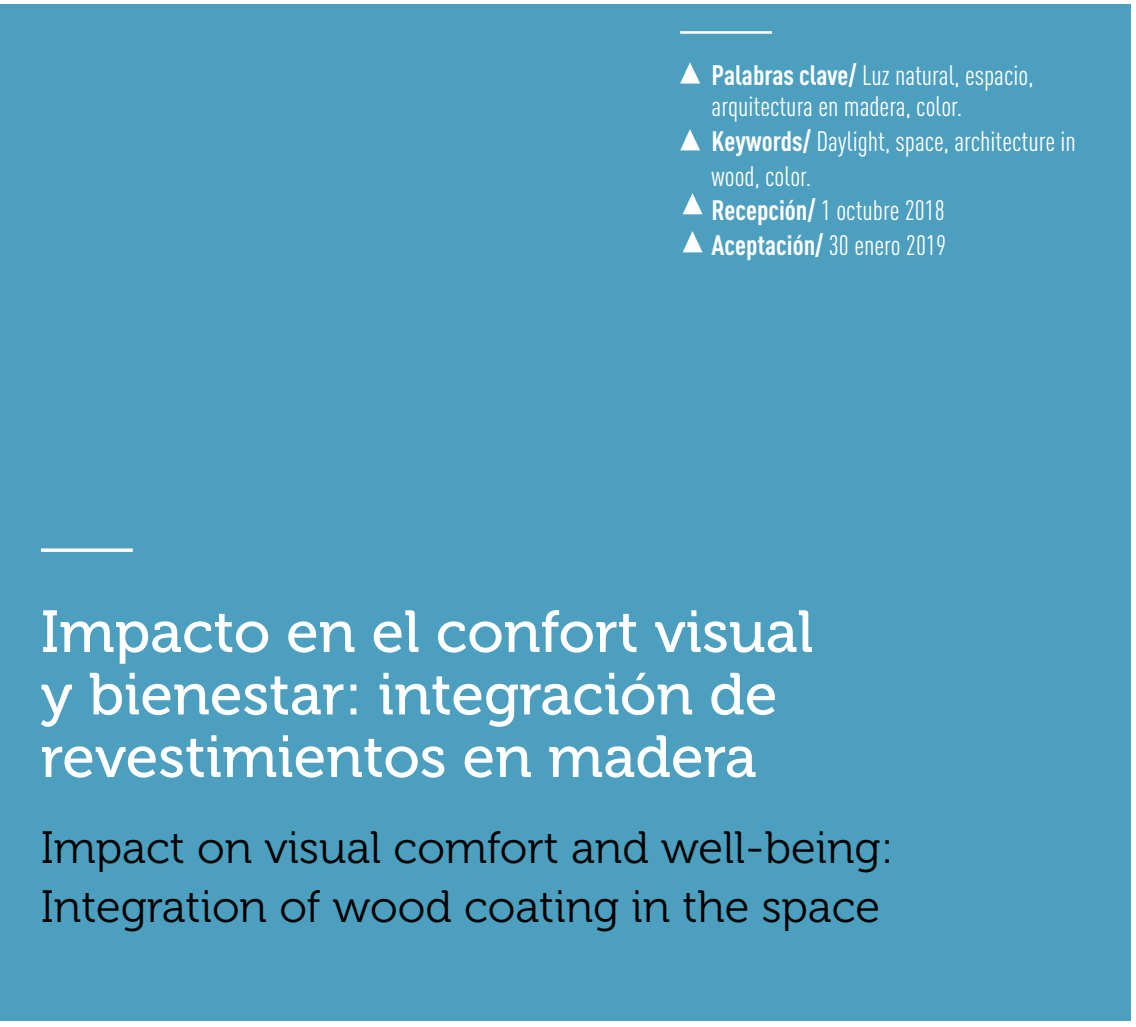

\section{Carolina Espinoza-Sanhueza}

Arquitecta, Universidad del Bío-Bío, Chile. Magíster en Hábitat Sustentable y Eficiencia Energética, Universidad del Bío Bío, Chile. cbespino@egresados.ubiobio.c

\section{María Beatriz Piderit-Moreno}

Arquitecta, Universidad del Bío-Bío, Chile.

Doctora en Art de Bâtir et Urbanisme

Universidad Católica de Lovaina, Bélgica.

Académica Departamento de Diseño y Teoria de la Arquitectura y Directora del Magíster en Hábitat Sustentable y Eficiencia Energética, Universidad del Bío-Bío, Chile. mpiderit@ubiobio.cl

\section{Pierre Blanchet}

MSc. Ph.D Wood Science, Université Laval,

Quebec, Canadá.

Full Professor, Department of Wood and Forest Science - CIRCERB, Université Laval, Quebec, Canadá.

pierre.blanchet@sbf.ulaval.ca

\section{Torsten Lihra}

MSc. Ph.D Wood Science, Université Laval,

Quebec, Canadá

Research Assistant, Department of Wood and Forest Science - CIRCERB, Université Laval,

Quebec, Canadá

torsten.lihra@sbf.ulaval.ca

RESUMEN/ El acceso a la luz natural y un buen confort luminoso puede mejorar el ambiente interior. Si bien los espacios que integran revestimientos blancos distribuyen de mejor forma la luz natural, el uso de la madera puede entregar otras atribuciones. De acuerdo con la teoría de la biofilia, el uso de la madera produce efectos psicológicos positivos en las personas y cambia la apreciación de los recintos interiores. El objetivo de esta investigación es evaluar la relación entre el ambiente luminoso y el grado de satisfacción visual frente a tres configuraciones del espacio en los que se varía el tipo y el porcentaje de madera. Una relación entre el análisis cuantitativo y cualitativo mediante modelos a escala (1:10 - 1:20), fotografías de alto rango dinámico, sistema ClELab y encuestas muestran que el uso de la madera presenta una respuesta favorable en comparación con espacios que solo integran superficies blancas. ABSTRACT/ Daylight and lighting comfort may improve indoor environments While white coatings have the capability to better distribute natural light, the use of wood could provide additional features. According to the biophilia theory, the integration of wood has positive psychological impacts on human beings and changes the appreciation of indoor spaces. The main objective of this research is to evaluate the relationship between the luminous ambiance and the degree of visual satisfaction, considering three spatial configurations, varying wood types and proportions. The relationship between a quantitative and a qualitative analysis with scale models (1:10 - 1:20), high dynamic range photographs, CIELab system and surveys, reveal that the use of wood triggers favourable responses compared with rooms that use white coatings only.

INTRODUCCIÓN. Está comprobado que los espacios que integran superficies blancas pueden distribuir de mejor manera la luz en el interior debido a su alto coeficiente de reflectancia (0,9\%). Sin embargo, es posible que la integración de elementos como la madera entreguen otro tipo de beneficios ligados al aspecto psicológico y fisiológico del ser humano, además de minimizar la desconexión entre la naturaleza y el ambiente interior (Watchman, Potvin y Demers 2017). La integración de elementos naturales favorece el bienestar de los ocupantes. La biofilia corresponde a la atracción innata que tiene el ser humano hacia elementos ‥ vivos, por lo que ventana y luz natural son el primer contacto que tenemos hacia la naturaleza y el exterior, teniendo en cuenta que pasamos alrededor de un $80 \%$ de nuestro tiempo en recintos interiores (Demers 2001). En este contexto Kellert (2005) ha relacionado los efectos de la naturaleza en el ser humano, con conceptos como bienestar, confort visual y naturalismo. Asimismo, Fell (2010) afirma que la integración de la madera puede disminuir el estrés de las personas luego de una actividad intelectual intensa. En el marco de otras investigaciones, también ha demostrado que el ser humano describe los espacios que integran madera con adjetivos como "natural" y "relajante", los cuales han sido relacionados con descripciones utilizadas en la biofilia, más específicamente con los conceptos de "naturalismo" y "bienestar". Si bien esto está relacionado principalmente con aspectos psicológicos del ser humano, Tsunetsugu (2007) ha determinado que los porcentajes de integración de madera en una habitación de $13 m^{2}$ (0\% - 45\% - 90\%) generan diferentes respuestas fisiológicas. En ello, aquella con un $90 \%$ de integración de madera produce más efectos fisiológicos positivos; sin embargo, la de 45\% de integración ha sido descrita como más "confortable" y "relajante", lo que sugiere una óptima integración de la madera en interiores. Por su parte, Kelz (2011) ha demostrado que, así como disminuyen los niveles de estrés, 
también lo hacen las pulsaciones cardiacas reduciéndose a 8000 latidos por día en el caso de estudiantes.

La experiencia de la luz natural en un espacio que integra madera está relacionada con el efecto sensorial que puede tener el ser humano, como también lo es el olfato o el tacto, lo que hace necesario estudiar con mayor profundidad el efecto visual de este material. Esta investigación busca establecer una relación entre el ambiente luminoso y el grado de satisfacción visual frente a tres configuraciones espaciales donde se varía el tipo y el porcentaje de madera. A través de modelos a escala (1:10 o 1:20), se analiza el comportamiento luminoso mediante el uso de fotografías de alto rango dinámico (HDR, por sus siglas en inglés), las cuales se utilizan para calcular la distribución de luminancias (MOP 2011) y temperatura de color, a través del sistema CIELab (CIE 1971). Se aplicó una encuesta de satisfacción visual a estudiantes y trabajadores para relacionar datos en los cuales se concluyen los efectos de la madera en el interior.

Esta investigación se desarrolla durante una estadía de investigación para optar al grado de magíster en la ciudad de Quebec (Canadá), en el marco de una alianza de cooperación entre la Université Laval y la

\section{Universidad del Bío Bío.}

\section{CASOS DE ESTUDIO: integración de la madera en modelos a escala.}

La madera se puede aplicar en distintos tipos de recintos, cambiando la forma de integración dentro del espacio. Debido a que este estudio apunta a representar distintas configuraciones y porcentajes, se buscan métodos validados de representación. La luz es un elemento dinámico que se comporta de la misma manera al interior de los espacios, sin importar su escala con respecto al ser humano; por lo tanto, puede ser estudiada con diferentes métodos. Entendiendo esta premisa, Lau (1972) establece diferentes modelos de reproducción de la realidad en

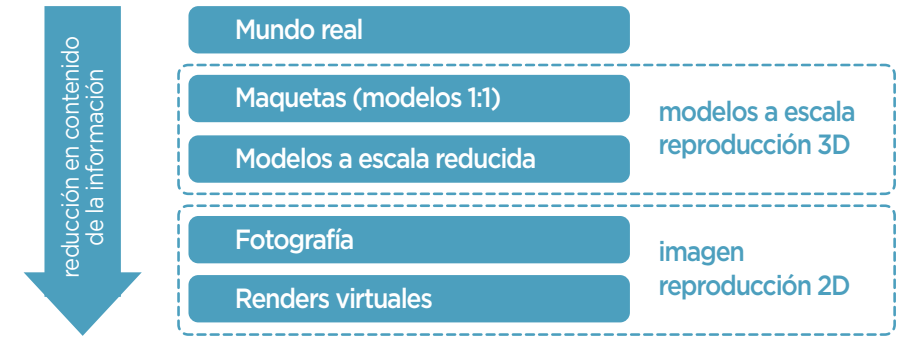

Figura 1. Modelos de representación de la realidad (fuente: Elaboración propia basado en Lau 1972).

\begin{tabular}{|c|c|c|c|}
\hline RECINTO & MEDIDAS & $\%$ ACRISTALAMIENTO & ESCALA \\
\hline Pasillo & $10 \times 2,5 \times 5$ & 8 & $1: 10$ \\
\hline Sala Multifuncional & $20 \times 10 \times 8$ & 40 & $1: 20$ \\
\hline Aulas & $10 \times 7 \times 3$ & 45 & $1: 10$ \\
\hline
\end{tabular}

Tabla 1. Resumen de dimensiones de maquetas y escala empleada para el estudio (fuente: Elaboración propia).

el marco de los cuales asegura que estos disminuyen el contenido de su información a medida que reducen su costo (figura 1). Si bien la metodología de menor costo y fácil fabricación corresponde a renders o imágenes virtuales, presenta bajo contenido de información. De los demás métodos, los modelos a escala reducida parecen ser una buena opción debido a su veracidad con respecto a la realidad (se encuentran dentro del primer tramo de metodologías de representación), y también por la facilidad de fabricación en comparación con los modelos de escala 1:1.

\section{Tipos de recintos evaluados.}

Debido a que existen múltiples recintos destinados a tareas diferentes, se han tomado como ejemplo espacios que pueden ser utilizados para edificios educativos, de manera a contribuir a la integración de este material en establecimientos educacionales (tabla 1). El primero corresponde a un pasillo, que debido a su función de distribuir a las personas dentro de un espacio presenta bajo porcentaje de acristalamiento y alta profundidad desde la fuente de iluminación (que en su mayoría corresponden a ventanas laterales en altura). Se proyecta un pasillo genérico utilizando medidas pertenecientes al artículo 4.2 .17 y 4.2 .18 de la Ordenanza General de Urbanismo y Construcciones (OGUC) (MINVU 2017). Otro tipo de espacio definido fue una sala multifuncional que puede ser utilizada como sala de danza, gimnasio o incluso un comedor. Puesto que las medidas deben responder a tareas diferentes, se utilizará un espacio con medidas que comprendan la razón 2:1 y una altura promedio correspondiente a la de los gimnasios, para asegurar que el comportamiento luminoso sea similar a lo que se puede encontrar en la realidad. Por último, se proyectó un tercer espacio similar a una sala de clases, con las siguientes medidas: $10 \times 7 \times 3 \mathrm{~m}$. Estas medidas han sido utilizadas anteriormente (Jafarian et al. 2017), respondiendo a usos como oficina, sala de clases, espacios destinados a salud, etc 

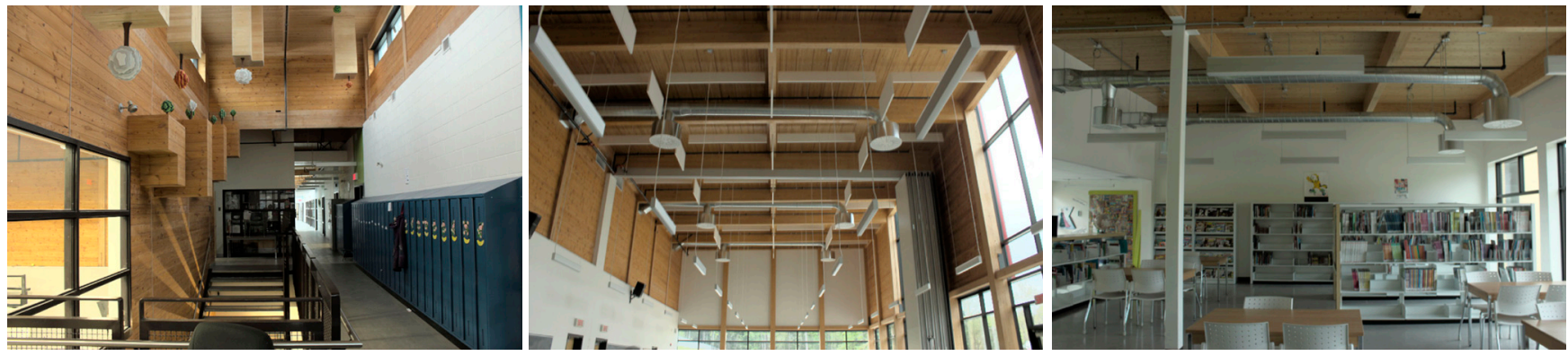

Imagen 1. Pasillo, sala multifuncional y aulas que integran madera en su superficie (fuente: Archivo de los autores).

\section{Integración de la madera: color y}

proporción. Tanto la superficie como la estructura de la madera están llenas de matices, ya que no es regular ni en bruto ni en paneles. Canadá presenta mayoritariamente revestimientos en forma de placas de maple azucarero (Acer saccharum) debido a la abundancia de esta especie. Como este tipo de madera ostenta colores muy claros (casi blancos), se tiñe para mejorar la calidez de los ambientes. Los colores varían según el tipo de edificio, pero es posible encontrar tonos claros y oscuros. Para este estudio era necesario conocer si el tipo y el porcentaje de madera afecta la satisfacción visual de las personas en comparación con un modelo (maqueta A) que integra solamente paramentos de color blanco. Por ese motivo, se ha analizado el contraste entre cada uno de ellos. Si bien se usan dos tintes para teñir la madera, los resultados arrojados son los que se muestran en la tabla 2.

Con respecto al porcentaje de integración de las superficies en madera, este se relaciona con los casos de estudio revisados en establecimientos educacionales de la provincia de Quebec. En ellos se ha podido encontrar que los pasillos y la sala multifuncional integran alrededor de un 40\% de madera en su superficie y de un $35 \%$ en las salas comunes (figura 2). Se determina integrar las superficies en madera en un porcentaje equivalente al observado en los casos de estudio.

En resumen, se construyen tres tipos de maquetas para cada recinto según se resume en figura 2 .

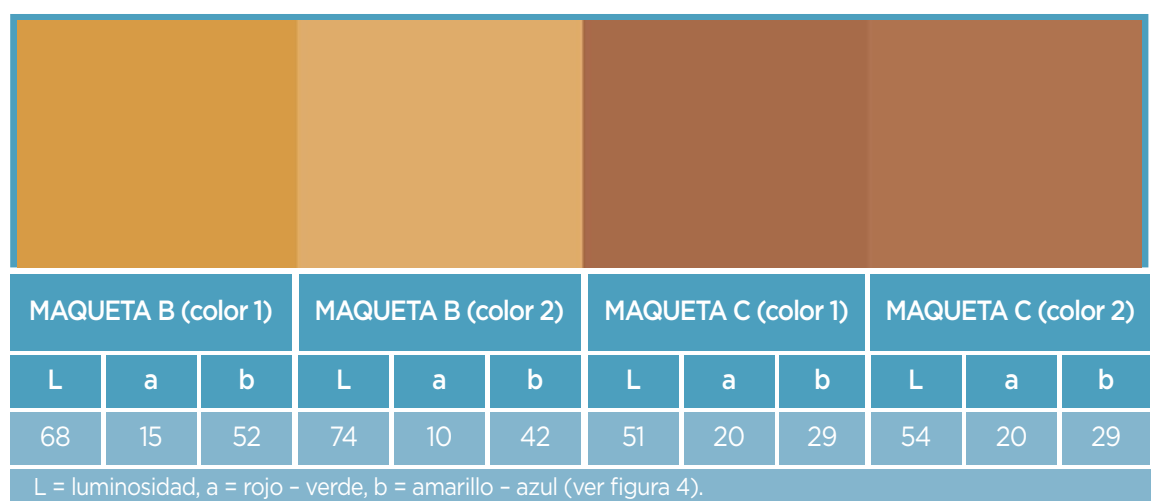

Tabla 2. Resultados de tintes aplicados a paneles de maple azucarero (fuente: Elaboración propia en base de Adobe CC Color)
MAQUETA B

MAQUETA C

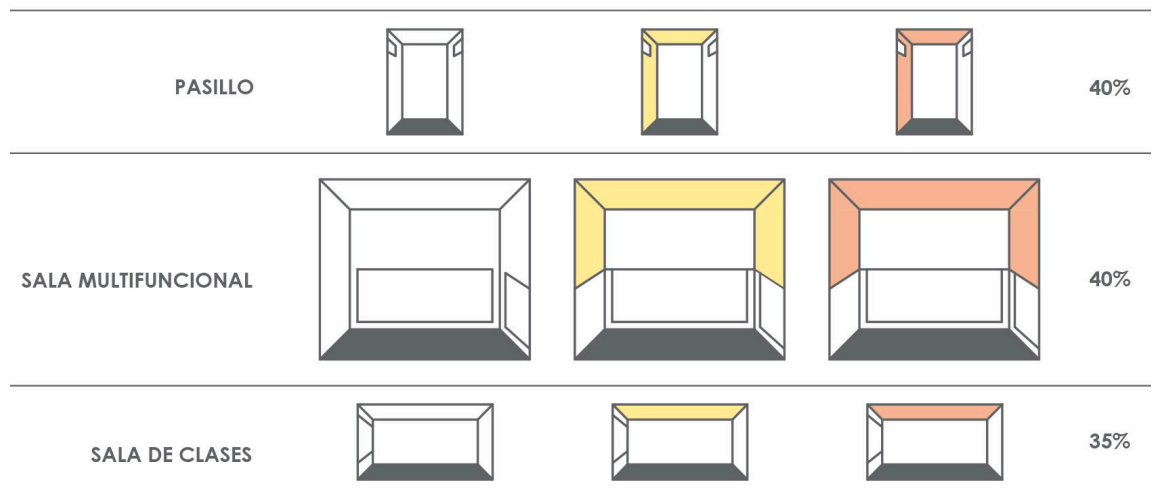

Figura 2. Resumen de maquetas utilizadas para estudio (fuente: Elaboración propia). 


\section{Evaluación del efecto de la luz y} satisfacción visual. Se utilizan métodos diferentes para medir el efecto de la luz en un ambiente luminoso. Sin embargo, el efecto visual de la luz en las superficies y el color tiene su propia metodología. En el caso de esta investigación, se determinó evaluar la distribución de luminancias y temperatura del color a través de fotografías HDR.

Las fotografías HDR reproducen en una imagen la luminosidad que el ojo humano percibe (Inanici y Heerwagen 2012;

Cauwerts y Piderit 2018). Esto corresponde a una secuencia de fotografías (entre 6 y 11) con grados diferentes de exposiciones que presentan un balance entre claros y oscuros. Sin embargo, este grado de exposiciones debe estar entre los valores de 20 y 200 , que se desglosa en el Histograma RGB de cada fotografía. De esta forma se elige el grado de exposición necesario para cada toma (figura 3).

Se utilizó una cámara Canon Rebel T2i para tomar las secuencias. Para su calibración y configuración, se recurrió a los métodos recomendados por Inanici (2005), tales como el uso de trípode, la variación en la velocidad de obturación, el uso de ISO 100, la modificación del balance de blancos a "luz día" y un ambiente estable y sin movimientos, entre otros. Luego, estas imágenes se convirtieron en una sola imagen de formato hdr mediante el software AftabLab, permitiendo analizar la distribución de luminancias. Las imágenes .hdr fueron formateadas en .jpg y procesadas en Adobe CC Color para obtener la reproducción de temperatura del color mediante el sistema CIELab.

Respecto del confort visual, la distribución de luminancias condiciona el nivel de adaptación del ojo, lo que afecta a la visibilidad de la tarea (MOP 2011). La luminancia es la luz recibida por nuestros ojos, reflejada por el objeto en dirección al observador. Para su análisis se utilizan valores de referencia recomendados en los TDR, los cuales indican que los niveles en las superficies de un espacio se deben encontrar en un rango de $30-100 \mathrm{~cd} / \mathrm{m}^{2}$.

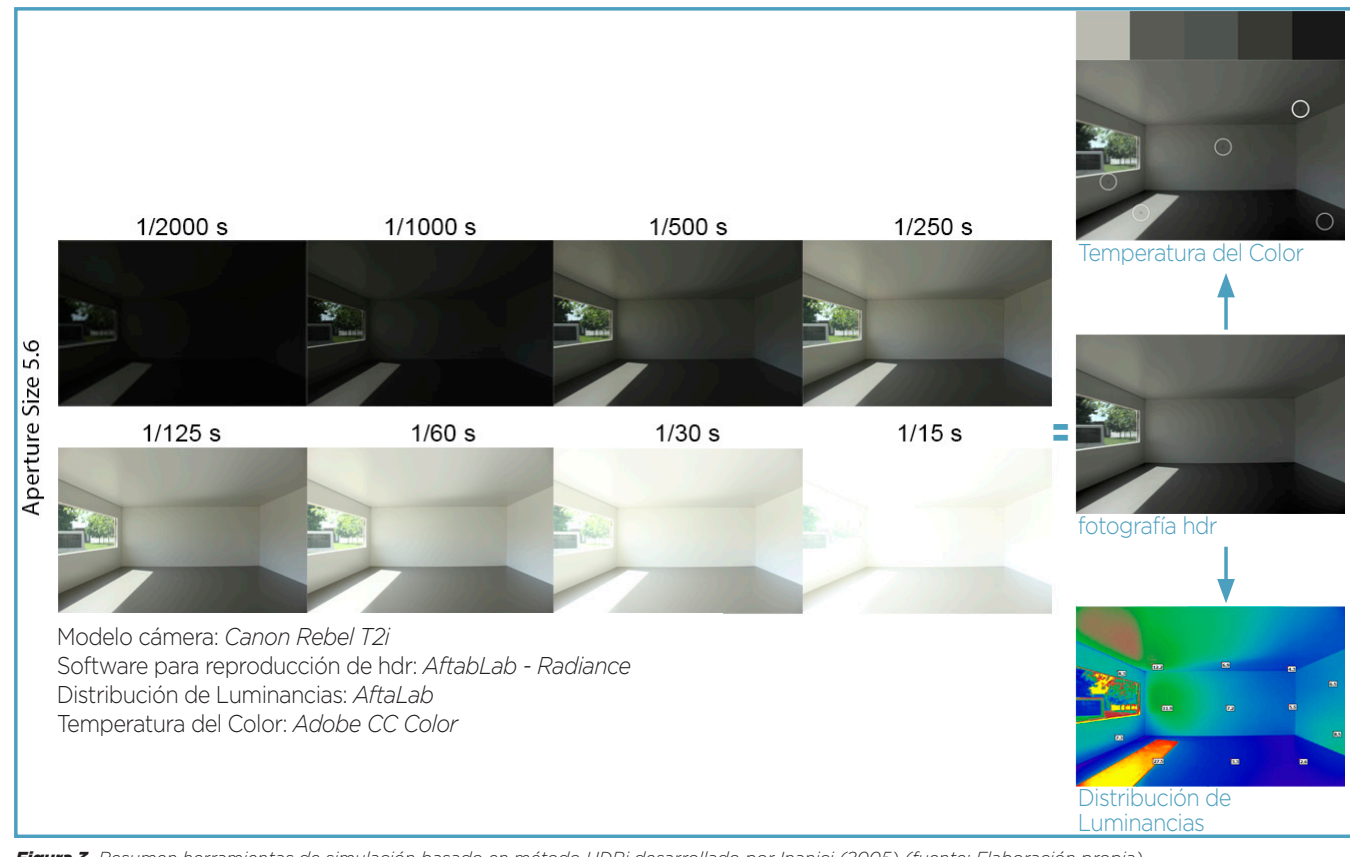

Figura 3. Resumen herramientas de simulación basado en método HDRi desarrollado por Inanici (2005) (fuente: Elaboración propia).

Por otra parte, la temperatura del color juega un papel importante, ya que gracias a ella es posible medir la calidez y la luminosidad de los espacios, y generar relaciones con respecto al ambiente interior y a la respuesta de los usuarios. Según Christment (1997), el color corresponde a la sensación que recibe el ojo humano en forma electromagnética, por lo que corresponde a una respuesta subjetiva que no puede ser medida con exactitud. Debido a la necesidad de establecer relaciones entre color y ser humano se utiliza el sistema CIELab, que correlaciona valores numéricos de color con la percepción visual, bajo variables de luminosidad, matiz y saturación. En la figura 4 se muestra que: L* equivale a luminosidad ( 0 correspondiente a negro, 100 correspondiente a blanco), $a^{*}$ define la posición de rojo $(+100)$ y verde $(-100)$ y b* define la posición de amarillo (+100) y azul (-100), pudiendo así conocer la temperatura del color a partir del uso de fotografías. Con respecto al análisis cualitativo, diferentes investigadores indican que los espacios que integran elementos

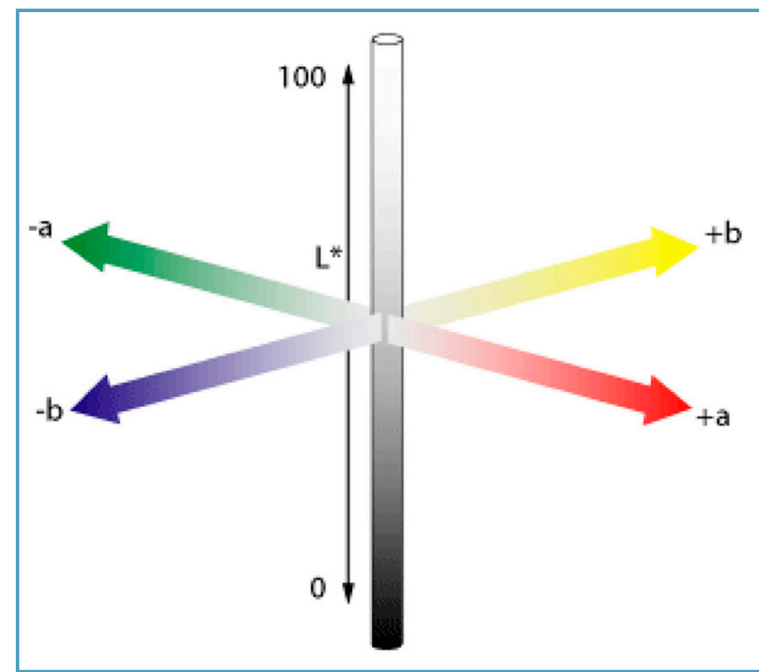

Figura 4. Espacio color CIELab (fuente: adobe.com y Jafarian et. al 2017). 
naturales han sido descritos con adjetivos relacionados con conceptos como "confort visual", "bienestar" y "naturalismo" (Kellert, Heerwagen y Mador 2008; Fell 2010). En este contexto, Poirier (2017) analiza el ambiente luminoso integrando estos conceptos y genera un cuestionario de satisfacción visual, el cual contempla items referentes a la apreciación global correspondiente a la primera impresión que se tiene del espacio en cuestión. El cuestionario contempla adjetivos para describir el ambiente luminoso mediante una escala que relaciona el número 7 con niveles positivos del ambiente luminoso y el número 1 con niveles negativos; luego se plantea una pregunta en la cual se debe escoger un adjetivo para describir el espacio

\section{en general (tabla 3 ).}

\section{Contexto de evaluación.}

La toma de muestra se ha realizado el día 27 de junio en la terraza del edificio

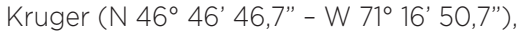
perteneciente a la Facultad de Forestería, Geomática y Silvicultura de la Universidad Laval, Quebec, Canadá. Se han entrevistado a 33 personas, entre ellos estudiantes, trabajadores y profesores de las áreas de ingeniería, química y administración, con un rango etario de 20 a 65 años.

\section{RESULTADOS.}

En general, los resultados respecto de los efectos visuales entre las maquetas A (que no integran madera), y las que sí la integran (B y C), presentan diferencias en materia de preferencias y adjetivos que describen el espacio utilizado por los encuestados. En el caso de la encuesta que indica: "Describa el ambiente interior con sus propios adjetivos", los adjetivos más utilizados para la maqueta B y C están relacionados con los conceptos de "luz", "naturalismo", "simbolismo" y "confort visual".

En la evaluación de las maquetas correspondientes a los pasillos, el modelo más aceptado corresponde al pasillo B, en el cual el $70 \%$ de los encuestados indica que sí permanecerían en este espacio. También ante la frase "Describa el ambiente interior con sus propios adjetivos" se han descrito estos espacios mayoritariamente como "naturales" y "placenteros", relacionados con

\section{¿ES ESTE UN ESPACIO EN EL CUAL LE GUSTARIA PERMANECER?}

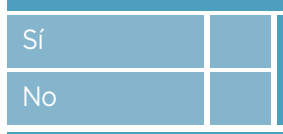

A PARTIR DE LOS SIGUIENTES ADJETIVOS, DESCRIBA EL ESPACIO INTERIOR:

La luz dentro del espacio es:

\begin{tabular}{|l|l|l|l|l|l|l|l|l|l|}
\hline Uniforme & 7 & 6 & 5 & 4 & 3 & 2 & 1 & Variable \\
\hline Clara & 7 & 6 & 5 & 4 & 3 & 2 & 1 & Oscura \\
\hline Suficiente & 7 & 6 & 5 & 4 & 3 & 2 & 1 & Insuficiente \\
\hline
\end{tabular}

Los colores en este espacio son:

\begin{tabular}{|l|l|l|l|l|l|l|l|l|l|}
\hline Cálidos & 7 & 6 & 5 & 4 & 3 & 2 & 1 & Fríos & \multirow{2}{*}{ COLOR } \\
\hline Vivos & 7 & 6 & 5 & 4 & 3 & 2 & 1 & Aburridos & \\
\hline Alegres & 7 & 6 & 5 & 4 & 3 & 2 & 1 & Tristes & \\
\hline
\end{tabular}

La terminación de las superficies del cuarto es:

\begin{tabular}{|l|l|l|l|l|l|l|l|l|l|}
\hline Confortable & 7 & 6 & 5 & 4 & 3 & 2 & 1 & Deslumbrante & \multirow{2}{*}{ CONFORT VISUAL } \\
\cline { 1 - 10 } Agradable & 7 & 6 & 5 & 4 & 3 & 2 & 1 & Desagradable & \\
\hline
\end{tabular}

El ambiente visual en general es:

\begin{tabular}{|l|l|l|l|l|l|l|l|l|l|}
\hline Estimulante & 7 & 6 & 5 & 4 & 3 & 2 & 1 & Adormecedor & \multirow{2}{*}{ CONFORT VISUAL } \\
\hline Productivo & 7 & 6 & 5 & 4 & 3 & 2 & 1 & No Productivo & \\
\hline Relajante & 7 & 6 & 5 & 4 & 3 & 2 & 1 & Estresante & BIENESTAR \\
\hline Placentero & 7 & 6 & 5 & 4 & 3 & 2 & 1 & Molesto & SIMBOLISMO \\
\hline Tradicional & 7 & 6 & 5 & 4 & 3 & 2 & 1 & Moderno & NATURALISMO \\
\hline Natural & 7 & 6 & 5 & 4 & 3 & 2 & 1 & Artificial & NATOLO \\
\hline DESCRIBA EL AMBIENTE INTERIOR CON SUS PROPIOS ADJETIVOS: &
\end{tabular}

Tabla 3. Encuesta aplicada para evaluar la satisfacción visual en espacios que integran revestimientos en madera (fuente: Poirier 2017).

conceptos de naturalismo y bienestar (figura 6). Estos coinciden con los resultados de la encuesta sobre "El ambiente visual en general", ya que alrededor del $90 \%$ de los encuestados indica que el espacio es más natural que artificial y el $80 \%$ indica que el espacio es más placentero que molesto (figura 7).
El análisis de temperatura del color mediante el sistema CIELab ha arrojado bajos niveles de luminosidad en los muros que integran superficies en madera, a pesar de que corresponden a imágenes tomadas a las 12:30 horas, cuando la radiación es mayor en comparación con otros momentos del día (tabla 4). 


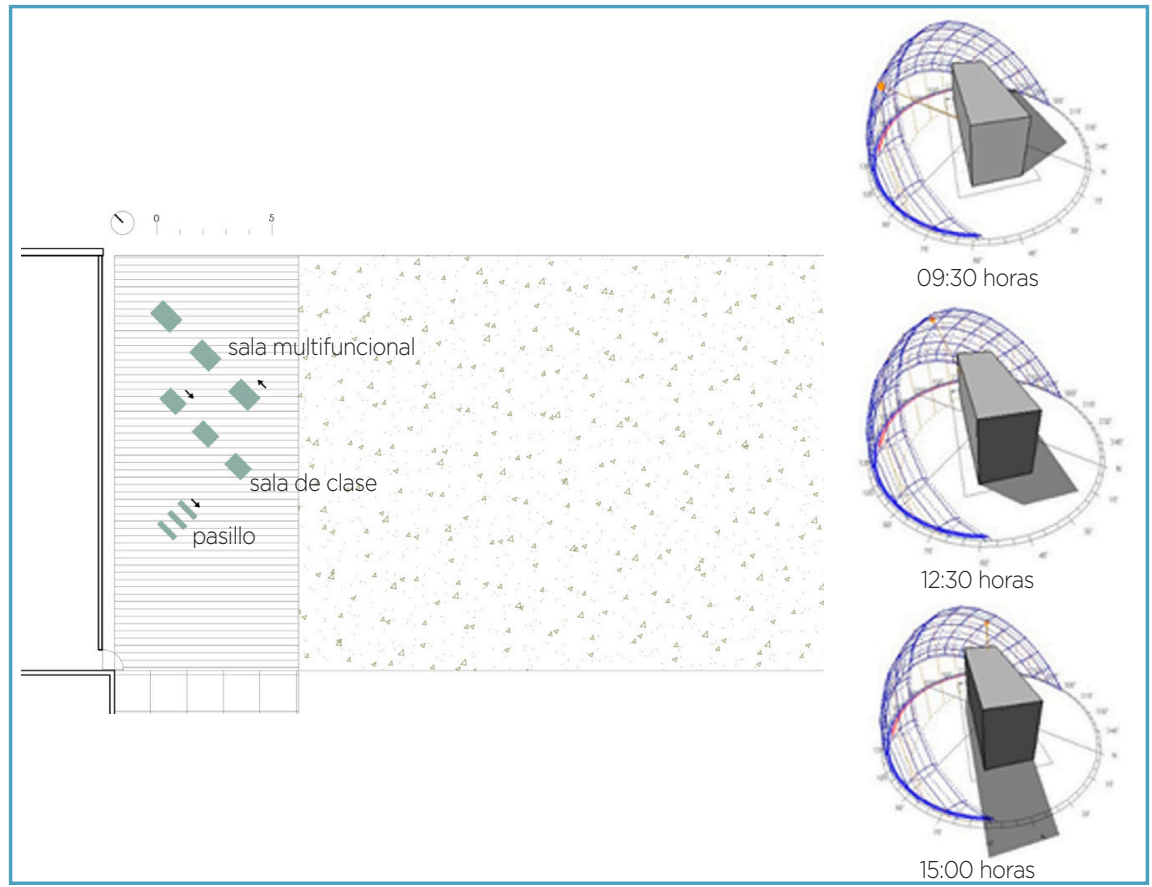

Figura 5. Posición de maquetas dentro del contexto de evaluación y mapa solar para el día 27 de junio. 09:30 - 12:30 - 15:00 horas (fuente: Elaboración propia - Ecotect Analysis).

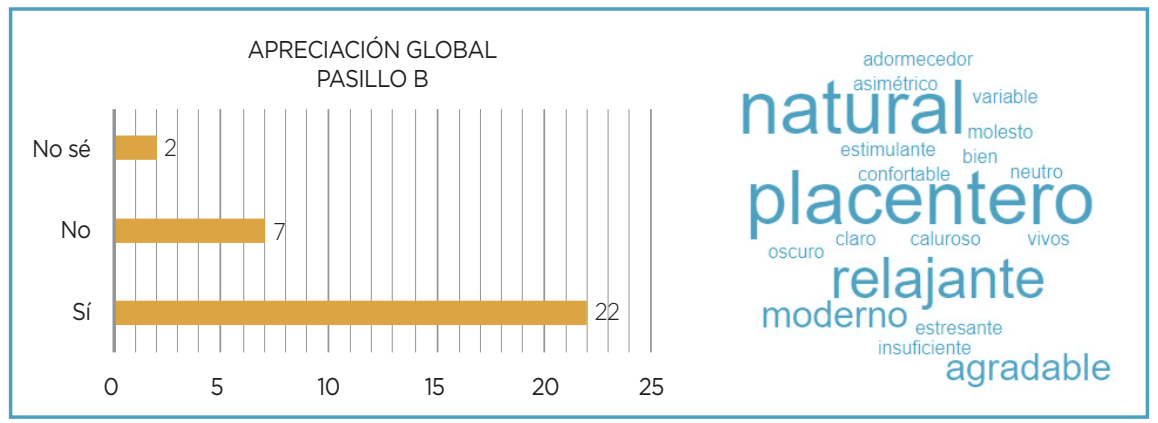

Figura 6. Respuesta de apreciación global con respecto al pasillo B y adjetivos utilizados para describir el espacio (fuente: Elaboración propia)

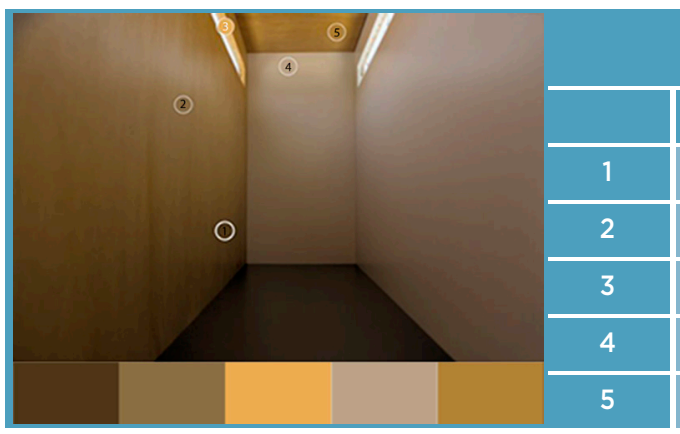

MAQUETA B

Tabla 4. Resultados arrojados por el análisis de temperatura del color - Pasillo B (fuente: Elaboración propia).

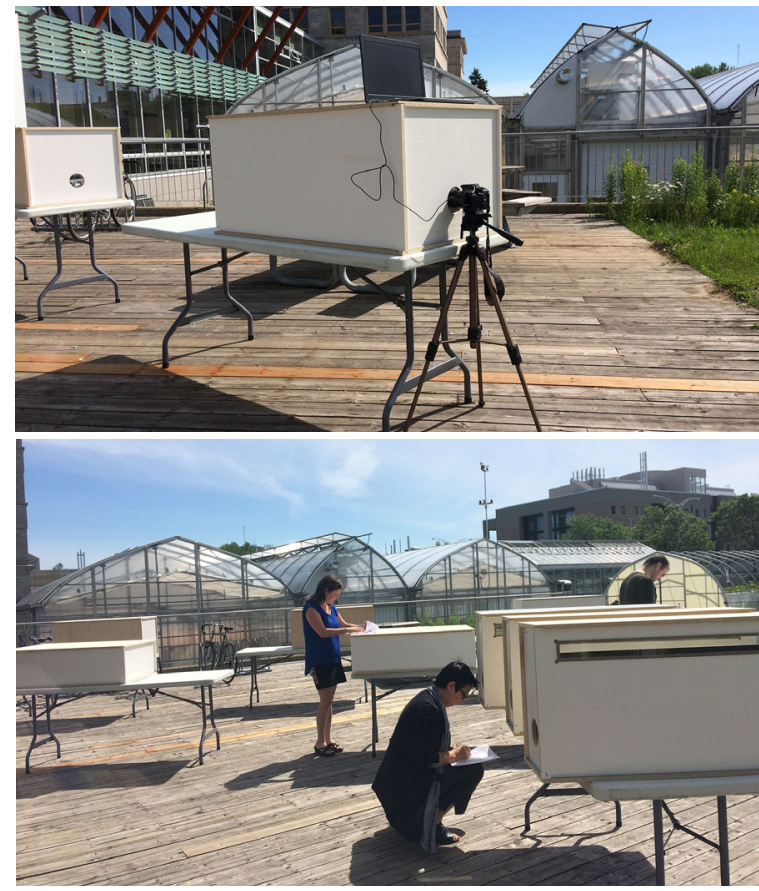

Imagen 2. Contexto experimental (fuente: Archivo de los autores.

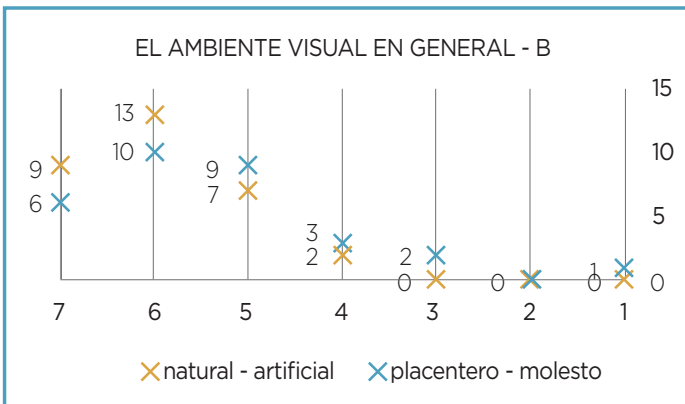

Figura 7. Respuesta de los ocupantes con respecto al ambiente artificial, placentero - molesto (fuente: Elaboración propia).
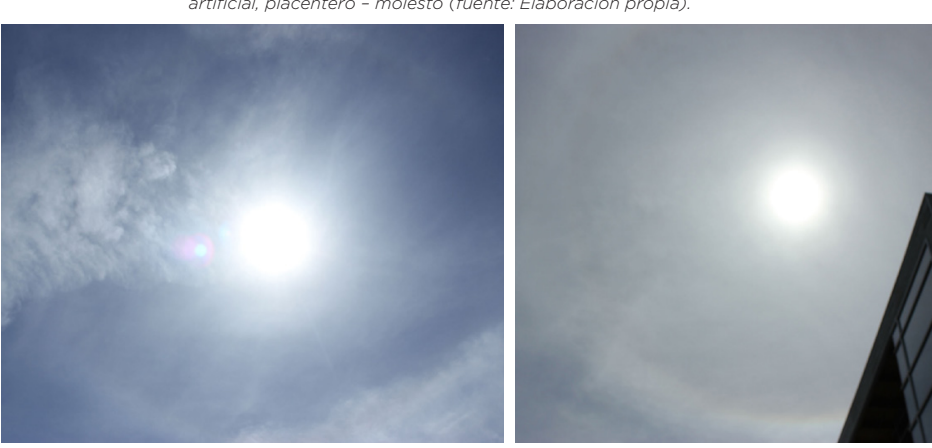

Imagen 3. Cielo predominante 27 de junio de 2018 (fuente: Archivo de los autores). 


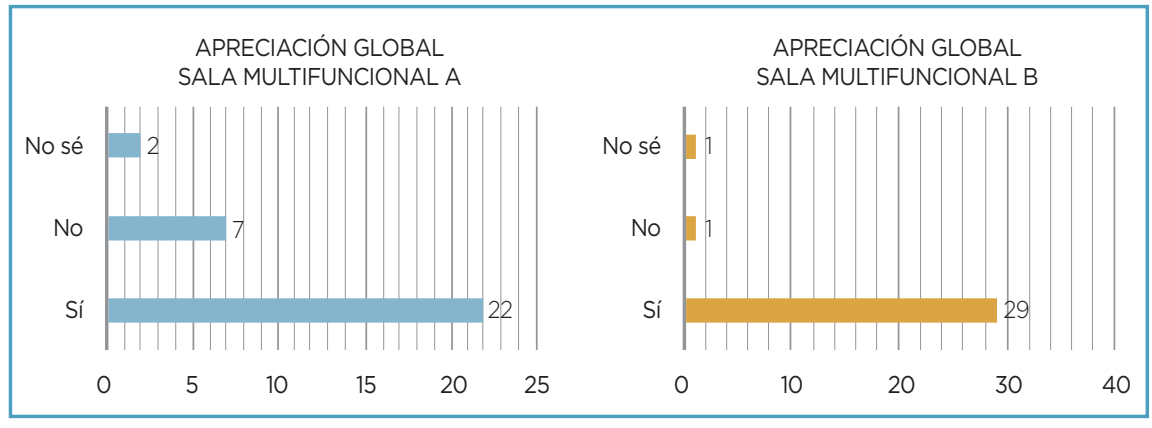

Figura 12. Resultados respecto a la apreciación visual de la Sala Multifuncional A y B. Mapa de luminancias y adjetivos para describir espacios (fuente: Elaboración propia).

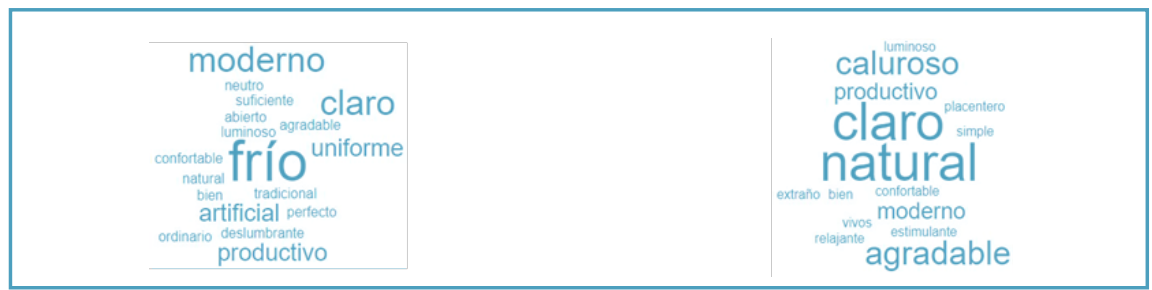

Figura 13. Adjetivos utilizados para describir maquetas A (izquierda) y B (derecha) (fuente: Elaboración propia)

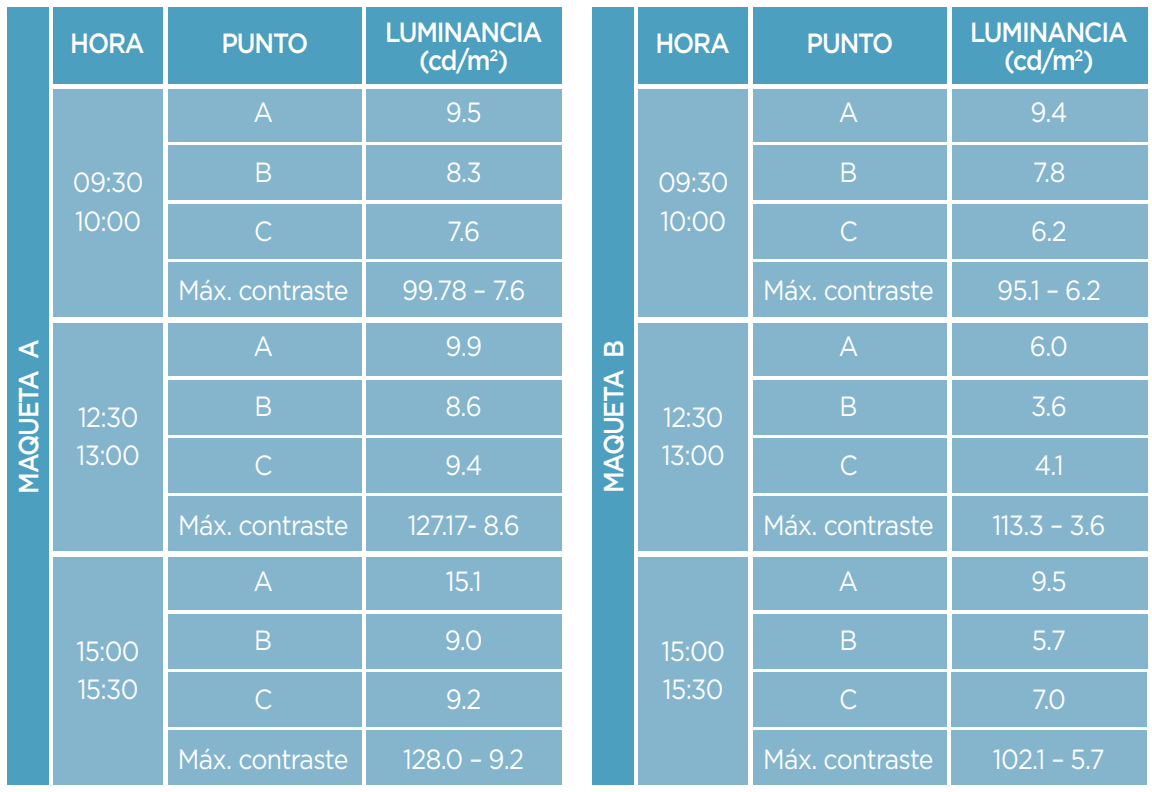

Tabla 6. Resultados de la distribución de luminancias en paramentos de maquetas A y B (fuente: Elaboración propia).
Los resultados de la evaluación realizada en la sala multifuncional muestran que los modelos más aceptados corresponden a aquellos que integran madera (maquetas B y C). Si bien las superficies en madera marcan una diferencia de 7 ocupantes entre el caso con menos aceptación (A) y el caso con más aceptación (B), el caso A sigue mostrando mayor equilibrio en el ambiente luminoso correspondiente a los resultados de luminancias (figura 14).

A pesar de que la maqueta $A$ es un espacio que presenta mayor equilibrio lumínico, este es descrito como un espacio frío, haciendo referencia a adjetivos negativos relacionados con el color dentro del espacio. Por el contrario, la maqueta B es descrita con adjetivos como "claro", a pesar de que los niveles de luminancia en sus superficies no sobrepasan las $9.5 \mathrm{~cd} / \mathrm{m}^{2}$ (tabla 6 ) en los revestimientos de madera. El adjetivo "natural" también está presente en las descripciones del espacio, haciendo alusión a conceptos de "naturalismo" (figura 13).

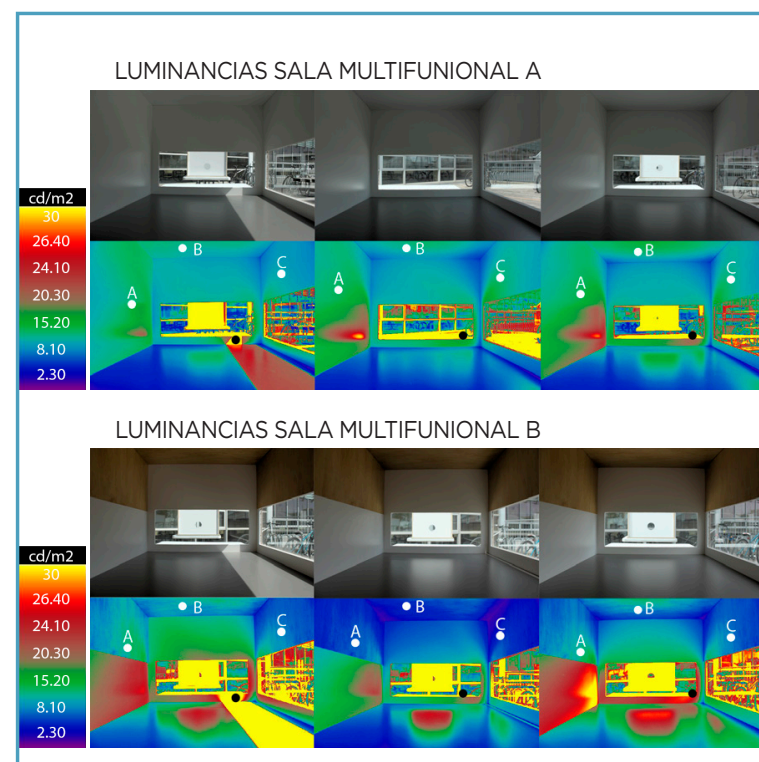

Figura 14. Mapa distribución de luminancias de la Sala Multifuncional $09 \cdot 30-12 \cdot 30-15 \cdot 00$ hrs maqueta A (arriba) y $B$ (abajo) (fuente: Elaboración propia). 
Los resultados de apreciación global correspondientes a la maqueta $\mathrm{C}$ muestran que un $80 \%$ de los encuestados sí permanecerían en ese espacio. A pesar de esto, los efectos visuales producidos por los revestimientos en la maqueta $\mathrm{C}$ han sido descritos como "oscuros" y "tradicionales" (figura 15).

"Oscuro" es coincidente con respecto a los resultados entregados por el análisis de luminancias, ya que presenta niveles mínimos de 2,6 $\mathrm{cd} / \mathrm{m}^{2}$ (tabla 7 y figura 16).

\begin{tabular}{|c|c|c|}
\hline HORA & PUNTO & $\begin{array}{l}\text { LUMINANCIA } \\
\left(\mathrm{cd} / \mathrm{m}^{2}\right)\end{array}$ \\
\hline \multirow{4}{*}{$\begin{array}{l}09: 30 \\
10: 00\end{array}$} & A & 3,9 \\
\hline & B & 2,6 \\
\hline & C & 3,4 \\
\hline & Máx. contraste & $97,5-2,6$ \\
\hline \multirow{4}{*}{$\begin{array}{ll}12: 30 \\
13: 00\end{array}$} & A & 9,4 \\
\hline & B & 8,1 \\
\hline & C & 12,0 \\
\hline & Máx. contraste & $135,6-8,1$ \\
\hline \multirow{4}{*}{$\begin{array}{l}15: 00 \\
15: 30\end{array}$} & A & 4,1 \\
\hline & B & 4,7 \\
\hline & C & 4,0 \\
\hline & Máx. contraste & $99,0-4,0$ \\
\hline
\end{tabular}

Tabla 7. Resultados de distribución de luminancias de la Sala Multifuncional C (fuente: Elaboración propia).

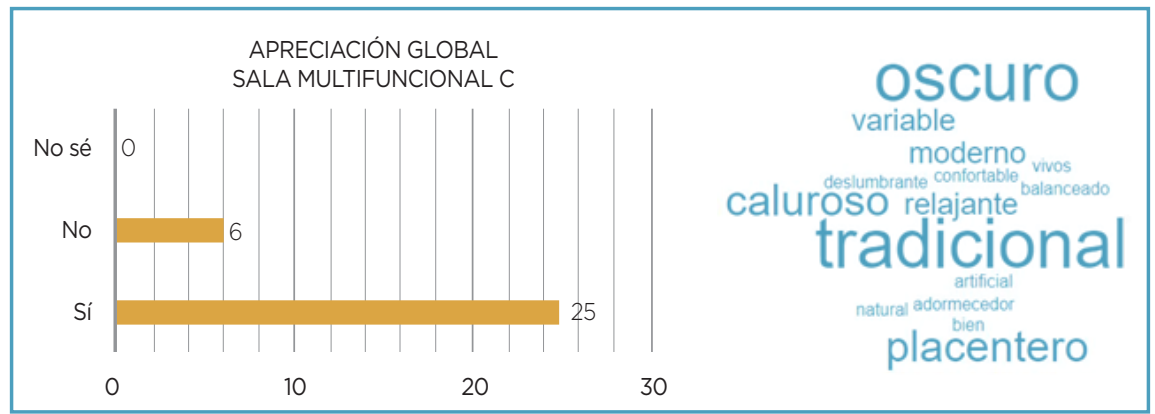

Figura 15. Respuesta de apreciación global y adjetivos utilizados para describir el ambiente interior. Sala Multifuncional C (fuente: Elaboración propia).

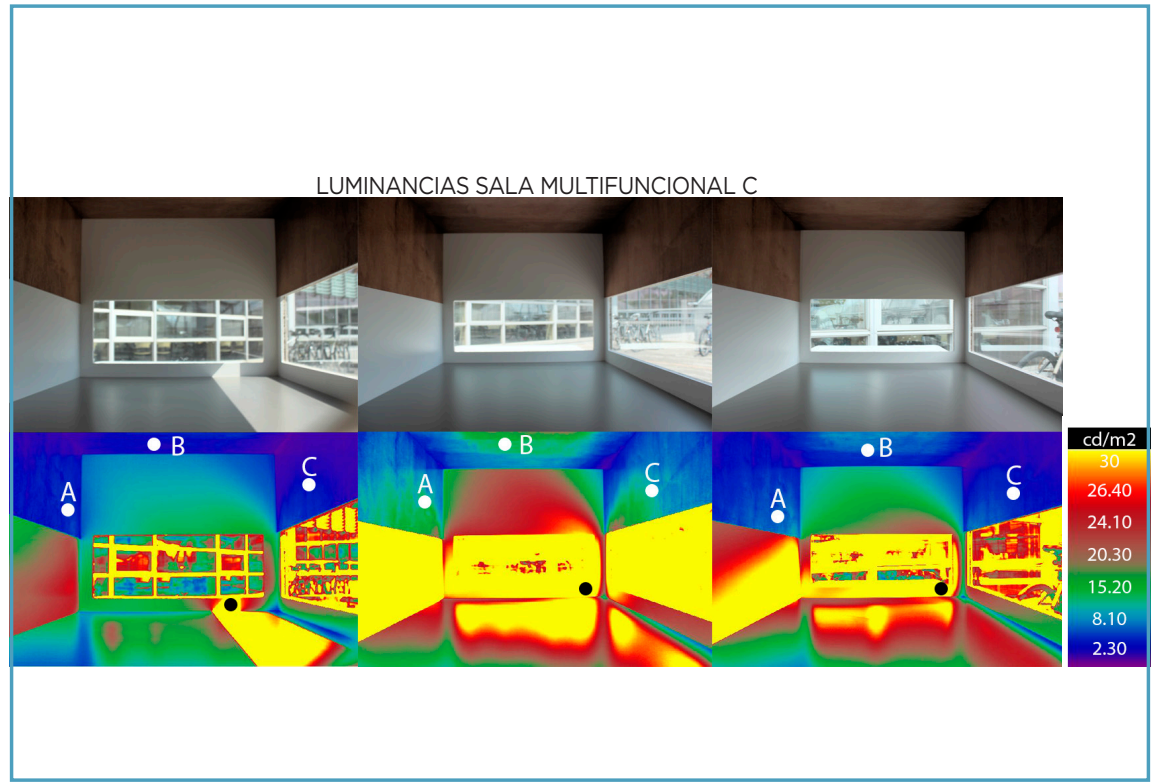

Figura 16. Mapa de distribución de luminancias de la Sala Multifuncional C 09:30 - 12:30 - 15:00 hrs (fuente: Elaboración propia).

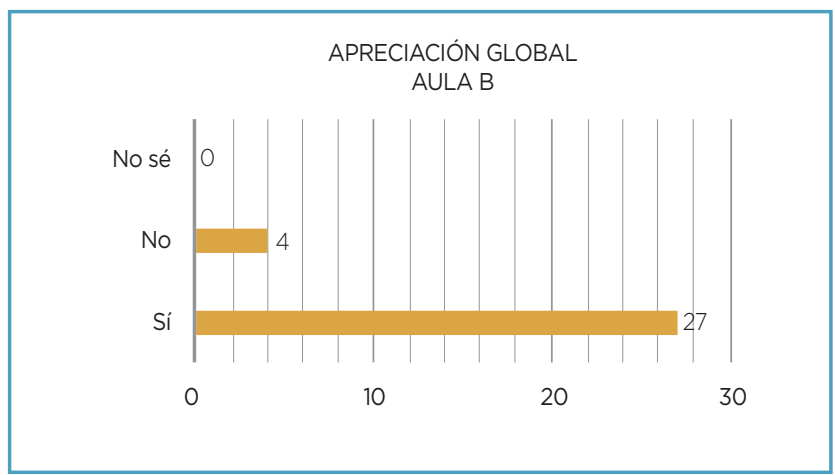

Figura 17. Respuesta de apreciación global y adjetivos para describir el ambiente interior en Aula B (fuente: Elaboración propia).

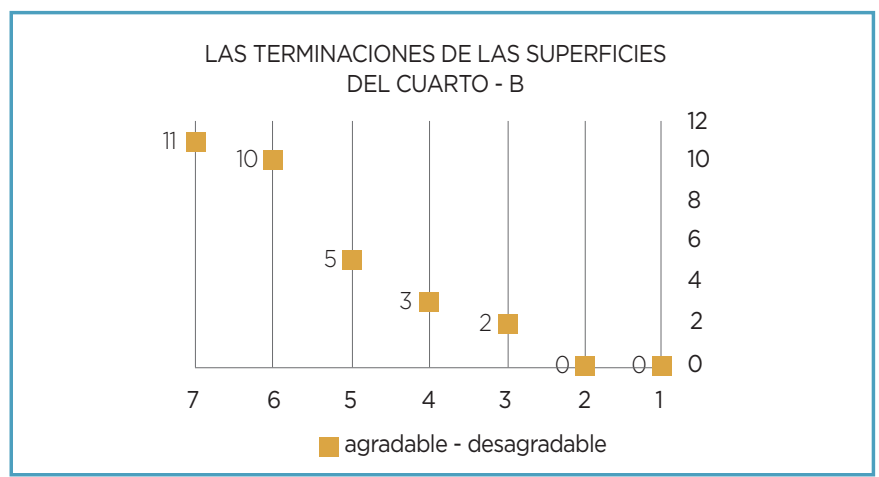

Figura 18. Respuesta de encuesta a la frase "Las terminaciones de las superficies del cuarto" del Aula B (fuente: Elaboración propia). 

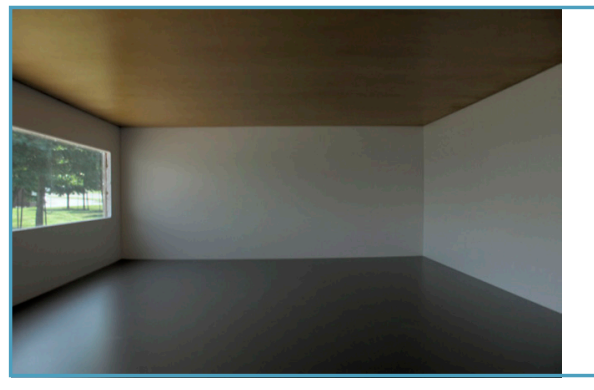

\section{natural \\ relajante oscuro \\ estimulante \\ agraatable \\ neutro claro \\ bien calmo \\ caluroso disonante \\ moderno}

Figura 19. Sala de Clases B y adjetivos utilizados para describir su espacio interior (fuente: Elaboración propia).

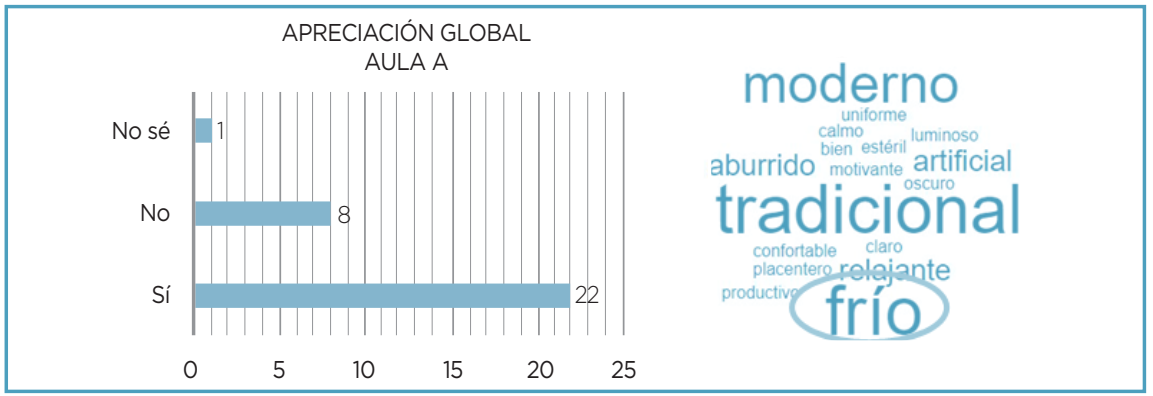

Figura 20. Respuesta de apreciación global y adjetivos utilizados para describir el ambiente interior en el Aula A (fuente: Elaboración propia).

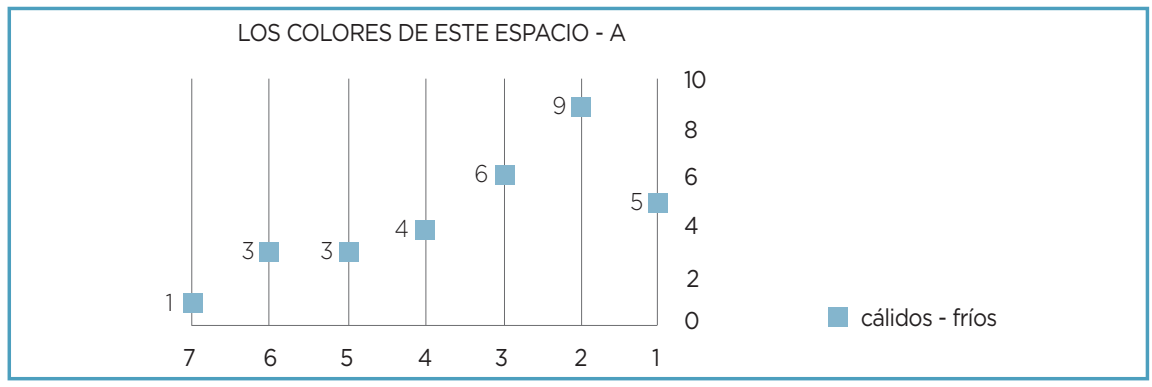

Figura 21. Respuesta de encuesta con la frase "Los colores de este espacio" en el Aula A (fuente: Elaboración propia).

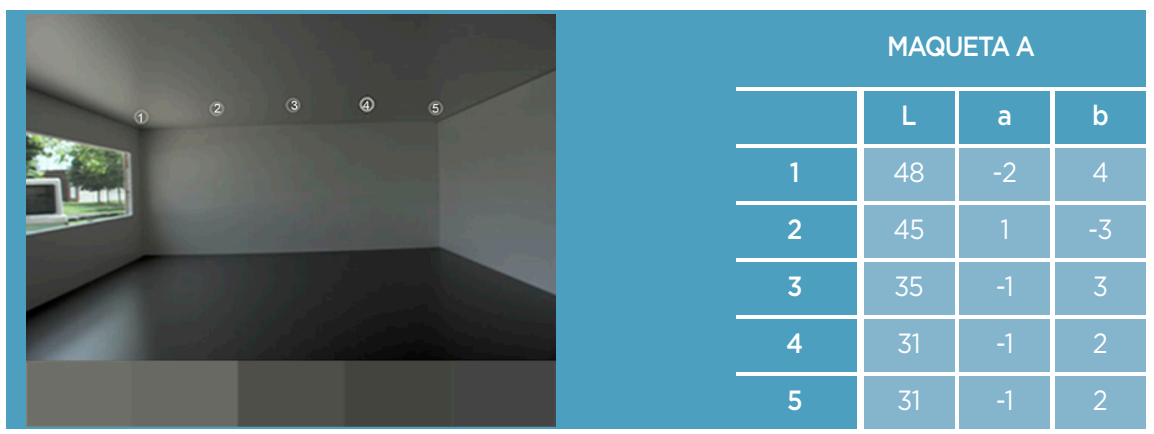

Tabla 8. Resultados arrojados en Sala de Clases A (fuente: Elaboración propia).

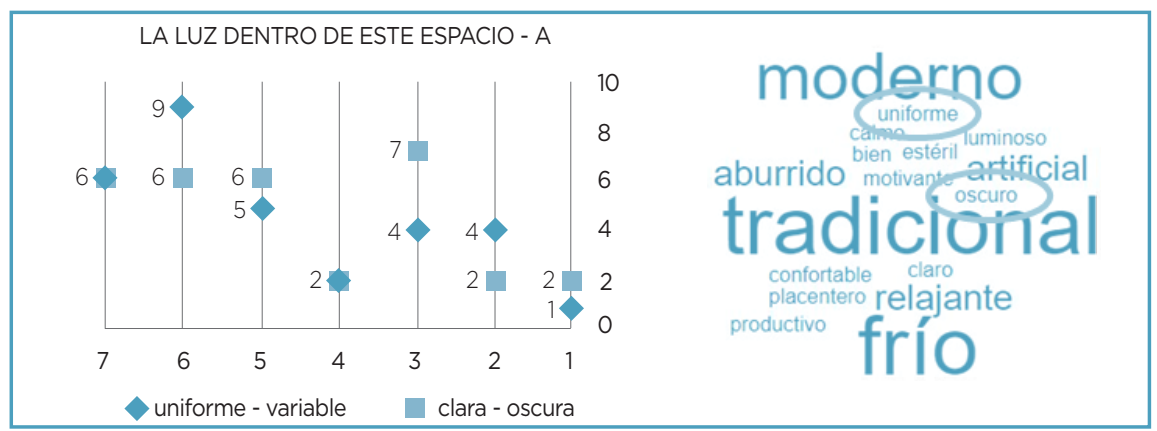

Para el análisis de la encuesta correspondiente a aulas, los resultados arrojan una preferencia por el caso B, luego una segunda preferencia por el caso A, dejando como última opción el caso C. En el modelo B, alrededor del 87\% de los encuestados asegura que es un espacio en el cual les gustaría permanecer (figura 17). Para describir el ambiente interior, el adjetivo utilizado coincide con los resultados de la encuesta ante la frase "Las terminaciones de las superficies del cuarto", ya que el $85 \%$ de los encuestados considera que es agradable, relacionado al concepto de confort visual en el espacio (figuras 18 y 19).

En el caso del modelo A, el 70\% de los encuestados ha indicado que sí permanecerían en ese espacio. Con respecto a los adjetivos utilizados, los resultados arrojan descripciones como "tradicional" y "frío", haciendo alusión a conceptos como "simbolismo" y "color", pero no a conceptos relacionados con confort visual dentro del espacio (figura 20). Es posible inferir que la impresión de los usuarios con respecto a este espacio está relacionada con experiencias espaciales que se repiten en el tiempo, pero que no producen un efecto estimulante.

Los resultados arrojados por el sistema ClELab coinciden con los adjetivos utilizados para describir el espacio. El espacio presenta baja luminosidad (todas interiores a 50) como también valores negativos para "a" (correspondiente a rojo) y "b" (amarillo) (tabla 8).

Analizando un poco más la luz dentro de este caso, se comprueba que los encuestados consideran el ambiente luminoso equilibrado, pero los ítems "claro - oscuro" y también "uniforme - variable" muestran una igualdad entre respuestas positivas y negativas (figura 22). En ese contexto, el concepto "luz" tampoco entrega respuestas significativas que se asocien al ambiente luminoso.

Figura 22. Respuesta a la encuesta con la frase "La Luz dentro de este espacio" y adjetivos (fuente: Elaboración propia). 


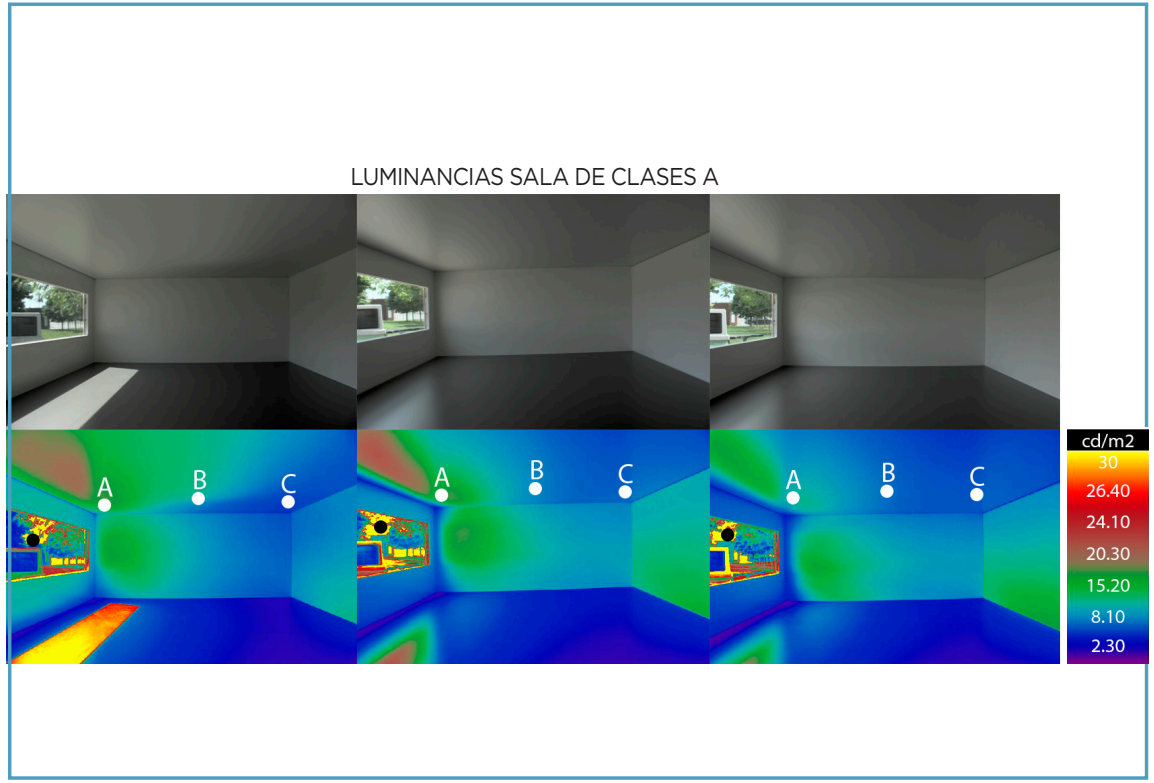

Figura 23. Mapa de luminancias de Sala de Clases A 09:30 - 12:30 - 15:00 hrs (fuente: Elaboración propia).

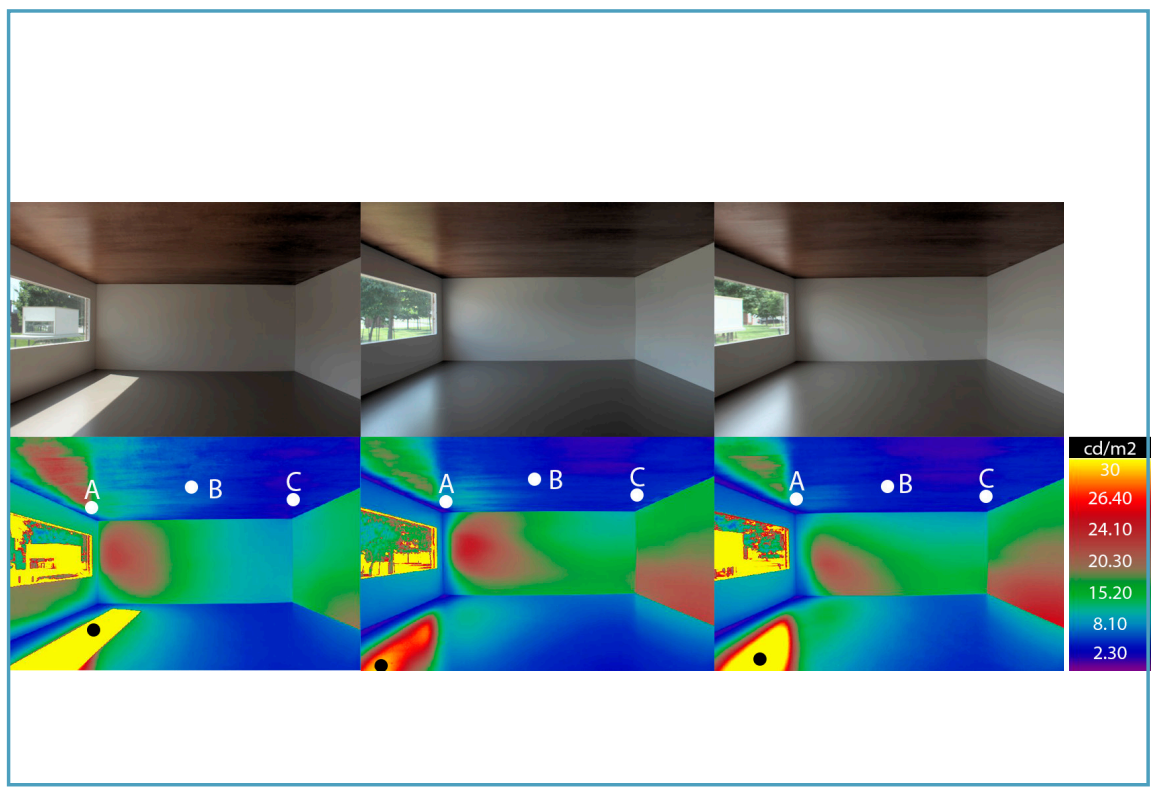

Figura 24. Mapa de luminancias de Sala de Clases C 09:30 - 12:30 - 15:00 hrs (fuente: Elaboración propia).

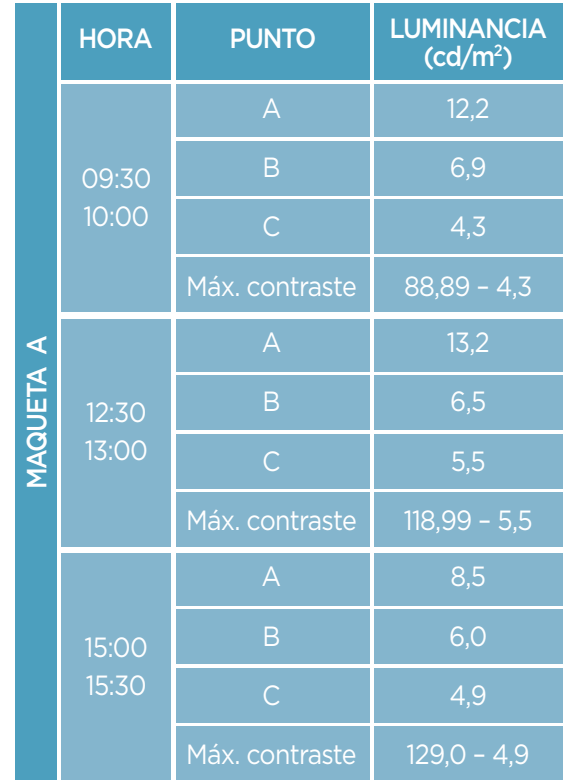

Tabla 9. Resultados de la distribución de luminancias en Sala de Clases A (fuente: Elaboración propia).

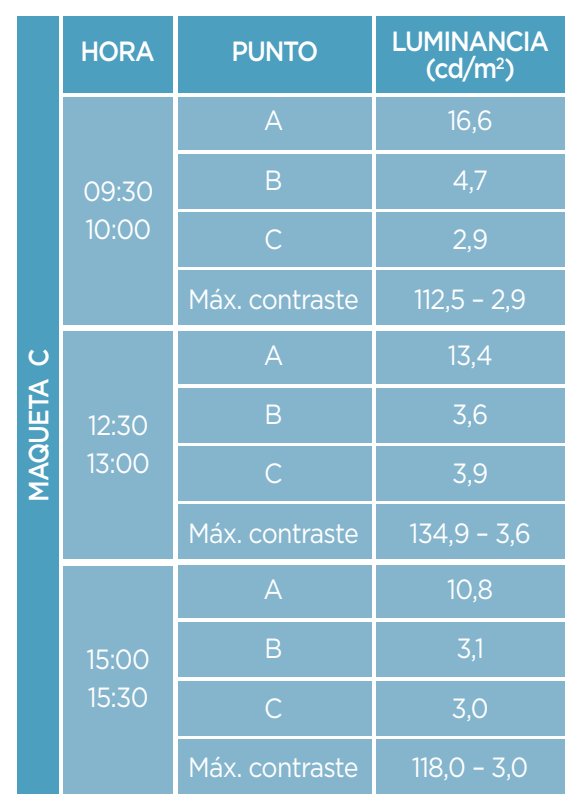

Tabla 10. Resultados de la distribución de luminancias en Sala de Clases C (fuente: Elaboración propia). 


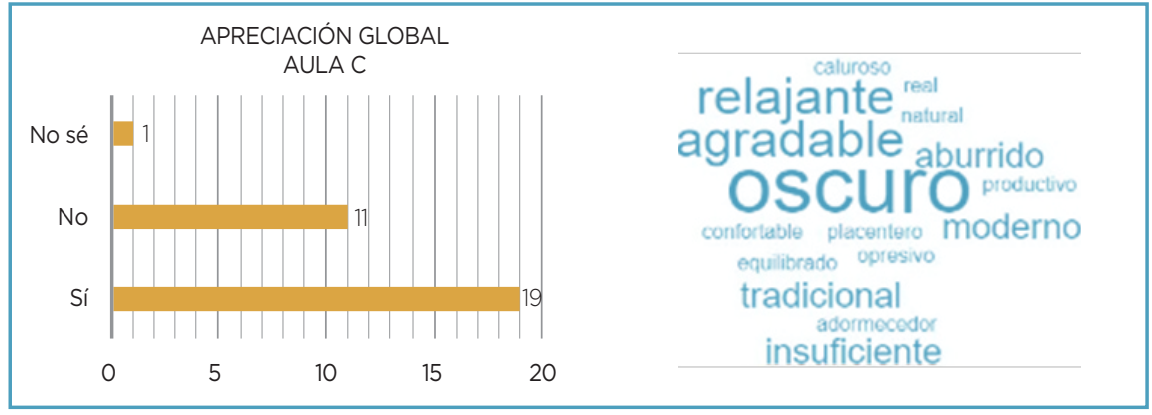

Figura 25. Respuesta de apreciación global y adjetivos utilizados para describir el ambiente interior en Aula C (fuente: Elaboración propia).
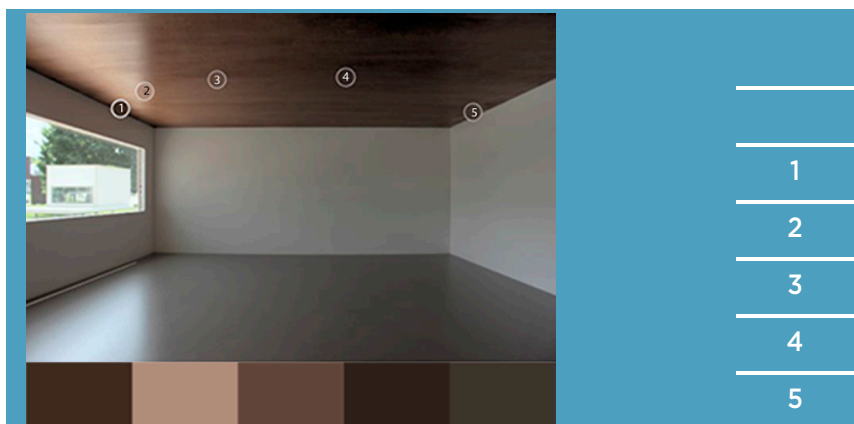

\section{MAQUETA C}

\begin{tabular}{|c|c|c|}
\hline$L$ & $a$ & $b$ \\
\hline 41 & 5 & 13 \\
\hline 35 & 7 & 10 \\
\hline 25 & 3 & 7 \\
\hline 18 & 2 & 4 \\
\hline 21 & 2 & 4 \\
\hline
\end{tabular}

En el caso de la maqueta C, el 60\% considera que sí permanecería en ese espacio, lo cual resulta insignificante en comparación a los demás recintos que integran madera.

En la descripción del espacio interior, el adjetivo "oscuro" es el más utilizado por los encuestados (figura 25). Esto es coincidente con los resultados arrojados en el análisis de distribución de luminancias y temperatura del color, ya que registran resultados bajos en comparación con los casos A y B. A pesar de este tipo de respuestas, y de los resultados que se muestran en el análisis de distribución de luminancias y temperatura del color (figura 24, tablas 10 y 11), este espacio ha sido descrito, de manera secundaria, con los adjetivos "agradable" y "relajante" (figura 26).

Tabla 11. Resultados de temperatura del color en Sala de Clases C (fuente: Elaboración propia).

LAS TERMINACIONES DE LAS SUPERFICIES DEL CUARTO - C

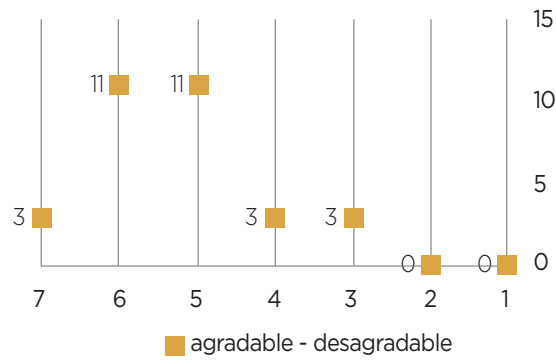

EL AMBIENTE VISUAL EN GENERAL - C

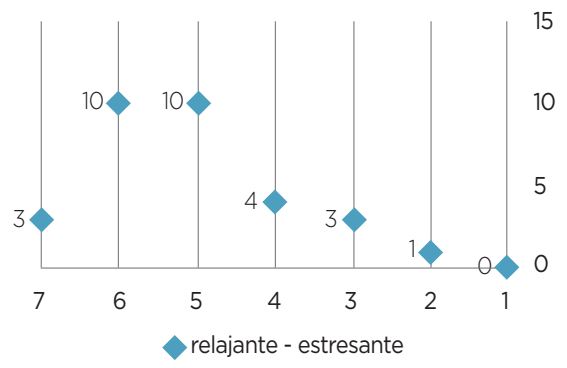

Figura 26. Resultados de encuesta con la frase "Las terminaciones de las superficies del cuarto" y "El ambiente visual en general" del Aula C (fuente: Elaboración propia) 


\section{CONCLUSIONES.}

De la evaluación de percepción visual a través de los modelos a escala es posible concluir que existen preferencias por los espacios que integran madera. Estos son evaluados de manera positiva por parte de los encuestados, en comparación con espacios que solamente integran superficies blancas, y en su mayoría con adjetivos ligados al bienestar y el confort visual en el ambiente luminoso. Estos resultados arrojan valores de luminancias más bajos en comparación con los demás espacios que no integran madera. Se puede concluir que no existe una relación directa entre espacios más luminosos y preferencia por parte de los usuarios, sino que la preferencia está relacionada con cualidades como calidez y naturalismo, vinculados a su vez con la materialidad y la biofilia.

El análisis de los adjetivos utilizados para cada concepto a la hora de describir el ambiente interior (tabla 12) sugiere que están relacionados con los conceptos de confort visual, bienestar y naturalismo. Se infiere que las respuestas entregadas por los encuestados están vinculadas con lo establecido por Kellert (2005), con respecto a que los elementos naturales pueden entregar beneficios psicológicos y fisiológicos relacionados con el bienestar y el confort del ser humano a causa de su búsqueda constante y su atracción innata hacia los elementos naturales.

También es posible inferir que es necesario utilizar colores de preferencia "claros", los cuales pueden ayudar a la distribución de la luz (como en los modelos B). Estos han tenido mejores respuestas con respecto a la apreciación global del espacio. En casos donde el espacio es de mayor envergadura, como la sala multifuncional C, los adjetivos utilizados para describirla están ligados al "color" y también al "bienestar", en comparación con el caso del pasillo C, donde los adjetivos están principalmente vinculados con descripciones negativas respecto del confort visual. Por lo tanto, si se va a utilizar una madera de color oscuro, se recomienda hacerlo en espacios de mayor volumen.

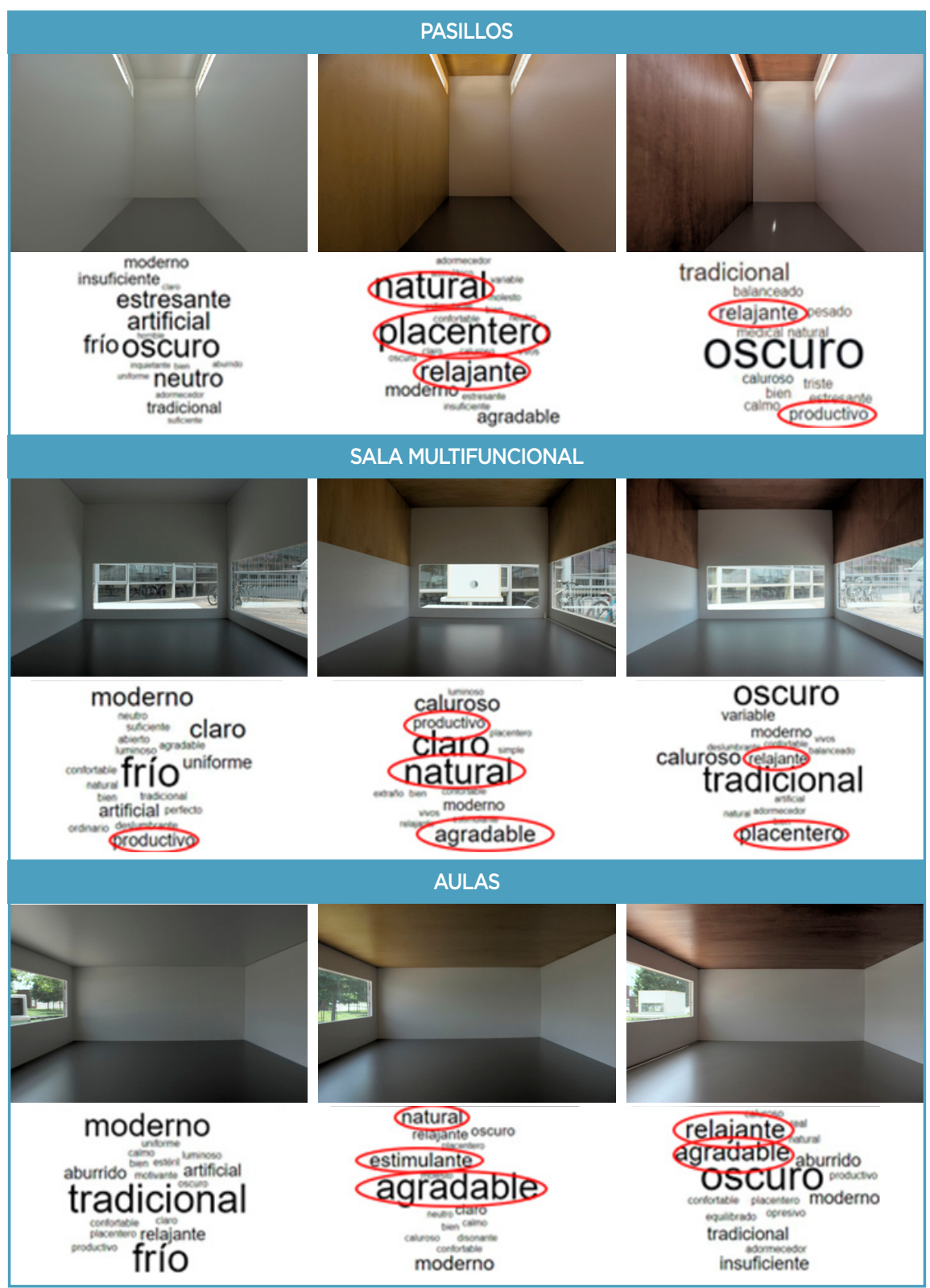

Tabla 12. Resumen de adjetivos utilizados para describir espacios y relaciones con conceptos de biofilia (fuente: Elaboración propia).
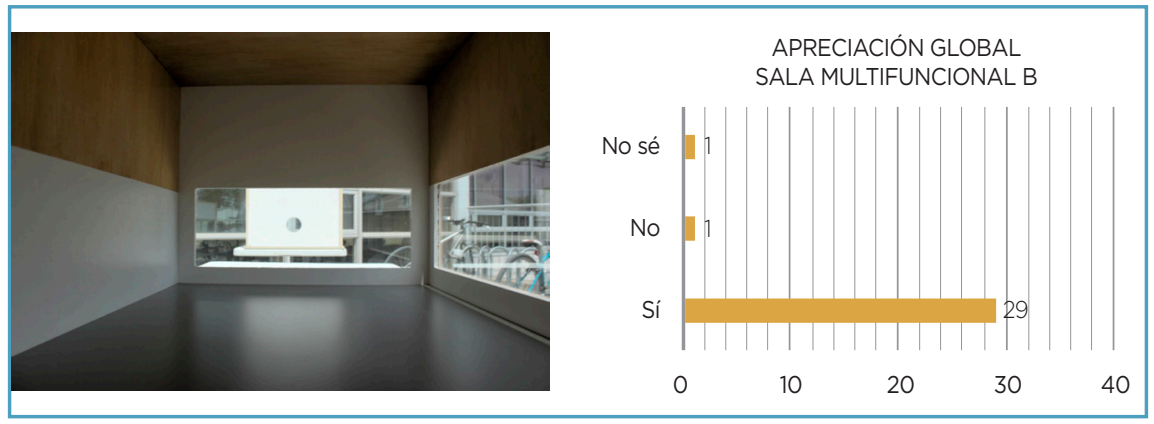

Figura 27. Respuesta de apreciación Global Sala Multifuncional B (fuente: Elaboración propia). 
El modelo con mayor aceptación corresponde a la Sala Multifuncional B, la cual cuenta con $40 \%$ de superficie de madera integrada. En ella, el 93\% de los encuestados afirmó que sí permanecería dentro de ese recinto (figura 27). Esto concuerda con el estudio realizado por Tsunetsugu (2007) que afirma que las personas muestran una preferencia por recintos cuyas superficies integran $45 \%$ de madera.

De acuerdo con los resultados entregados, la hipótesis de esta investigación resulta ser verídica debido a que la posición de la madera, como el color y las dimensiones del espacio, modifican la aceptación y la descripción del espacio visual que se está estudiando, como también la preferencia entre un espacio que integra madera en comparación con un espacio que solo integra superficies blancas.

Esta investigación busca principalmente entregar información en relación con aspectos subjetivos del ambiente interior y del uso de materiales naturales como la madera. Además, persigue fomentar el uso de la madera puesto que es uno de los materiales con menos emisiones de gases de efecto invernadero, altamente sustentable y de gran abundancia tanto en Canadá como en Chile.

\section{LIMITACIONES DE ESTA}

INVESTIGACIÓN. Las tomas fotográficas y la aplicación de encuesta de satisfacción han sido realizadas en la ciudad de Quebec, Canadá, la cual cuenta con un tipo de luz nórdica y de menor radiación solar en comparación con otras locaciones. También vale la pena mencionar que las fotografías han sido realizadas en los meses de abril, mayo, junio y julio, correspondientes a la primavera y el verano en el hemisferio norte, por lo que los resultados pueden variar

durante otras estaciones del año.

AGRADECIMIENTOS. Esta investigación se desarrolla gracias a la beca ELAP otorgada por el gobierno de Canadá, el apoyo del grupo de investigación de Arquitectura y Construcción Sustentable de la Universidad del Bío Bío y la Chair Industrial de Investigación de la Construcción Eco Sustentable en Madera (CIRCERB) de la Université Laval, Quebec - Canadá. ve

\section{REFERENCIAS}

Cauwerts, C. y Piderit, M., 2018. "Application of High-Dynamic Range Imaging Techniques in Architecture: A Step toward High-Quality Daylit Interiors?" Journa/ of Imaging 4 (1):19. Disponibe en: https://doi.org/10.3390/ jimaging 4010019

CIE, 1971. "Recommendations on Uniform Color Spaces, Color-Difference Equations, Psychometric Color Terms." Internationa/ Comission on I//umination 2 (Colorimetry).

Demers, C., 2001. "Lighting in «Études Environnementales Pour L'édifice de La Caisse et de Dépôt et de Placement Du Québec À Montréal »." Groupe de Recherche En Ambiances Physiques, École D’architecture, Université Laval, Québec, Canada, 27.

Fell, D., 2010. "Restorative Properties of Wood in the Built Indoor." Wood in the Human Environment: Restorative Properties of Wood in the Built Indoor Environment, no. February:144. Disponibe en: https://doi. org/10.14288/1.0071305

Inanici, M. y Galvin, J., 2004، “Evaluation of High Dynamic Range Photography As a Luminance Mapping Technique." Berkeley. http://gaia.lbl.gov/btech/papers/57545.pdf

Jafarian, H., Demers, C., Blanchet y P., Laundry, V., 2017. "Effects of Interior Wood Finishes on the Lighting Ambiance and Materiality of Architectural Spaces." Indoor and Built Environment O (0):1-19. Disponibe en https://doi.org/10.1177/1420326X17690911
Kellert, S., 2005. Science and Theory of Connecting Human and Natural Systems. Building for Life : Designing and Understanding the Human-Nature Connection. Disponibe en: https://doi.org/10.1007/s13398-014-0173-7 Kellert, S., Heerwagen, J. y Mador, M., 2008. Biophilic Design. Hoboken, New Jersey: John Wiley \& Sons, Inc MINVU, 2017, "Ordenanza General de Urbanismo Y Construcción." Santiago, Chile: Ministerio de Vivienda y Urbanismo

MOP, 2011. "Confort Lumínico." En Términos de Referencia Estándarizados TDRe., 31. Santiago, Chile. Disponibe en: http://arquitectura.mop.cl/centrodocumental/Documents/TDRe_MOP-DA_Parte3.pdf

Poirier, G., 2017. "Le bois comme générateur d'ambiances visuelles en architecture. Étude expérimentale comparative sur la satisfaction visuelle à l'aide de maquettes à échelle réduite." Tesis, Université Laval. Disponibe en: https://corpus.ulaval.ca/jspui/bitstream/20.500.11794/28280/1/33487.pdf Watchman, M., Potvin, A. y Demers, C., 2017. "A Post-Occupancy Evaluation of the Influence of Wood on Environmental Comfort." BioResources 12 (4):8704-24. Disponibe en: https://doi.org/10.15376/ biores.12.4.8704-8724 